\title{
Study of conducting ITO thin film deposition on flexible polyimide substrate using spray pyrolysis
}

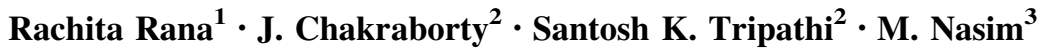

Received: 19 June 2015/ Accepted: 18 September 2015/Published online: 27 November 2015

(C) The Author(s) 2015. This article is published with open access at Springerlink.com

\begin{abstract}
Nanostructured indium tin oxide (ITO) thin films have been grown by chemical spray pyrolysis method on flexible polyimide (PI) polymeric substrates at various temperatures $\left(400,450\right.$ and $\left.500{ }^{\circ} \mathrm{C}\right)$ using solutions of indium and tin chlorides as precursors. The composition, microstructure, surface morphology, thermal, electrical, and optical characteristics have been analysed by FT-IR, UV-Vis, X-ray diffraction, SEM, EDAX, atomic force microscopy, electrical measurements, TGA, etc. X-ray diffraction measurements employing $\mathrm{Cu}-\mathrm{K} \alpha$ radiation showed that the ITO films were polycrystalline with a cubic bixbyite structure. An increment in average grain size, electrical conductivity and optical transmittance was observed at higher substrate temperature. ITO-coated films maintained the mechanical properties and stability of the pristine PI films. The adhesion between surface ITO layers and PI matrix was found acceptable.
\end{abstract}

Santosh K. Tripathi

sktripathi23@gmail.com

$\triangle$ M. Nasim

nasim_gfast@yahoo.co.in

Rachita Rana

ranarachita028@gmail.com

J. Chakraborty

jcdrdo@gmail.com

1 Banasthali Vidyapith, Tonk 304 022, Rajasthan, India

2 Defence Materials and Stores R \& D Establishment (DMSRDE), G. T. Road, PO: DMSRDE,

Kanpur 208013, UP, India

3 Defence Institute of Bio-Energy Research, Goraparao, PO: Arjunpur, Haldwani 263139, Uttarakhand, India

\section{Graphical Abstract}

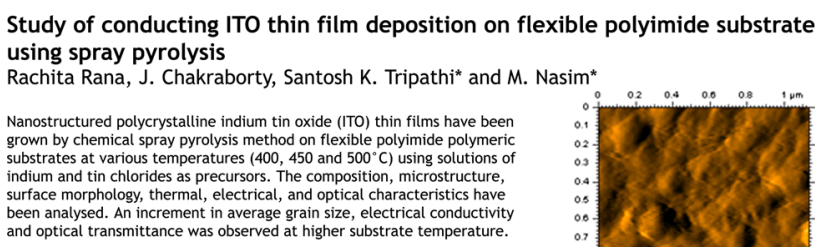

Keywords ITO - Polyimide - Spray pyrolysis · Conductive film $\cdot$ Characterization

\section{Introduction}

The deposition of conducting metal oxides on various substrates, particularly on polymeric surfaces [1-3] has been gathering great attention due to its potential applications in the field of flexible micro-electronics, circuit board optics, sensors, outer space materials, solar cells, wearable displays, aerospace and surface conductive flexible polyimide tapes [4-6]. Traditionally, the fabrication of metal oxide used to be carried out on the glass or ceramic substrate, but this trend has been successfully replaced by the polymeric matrix owing to the outstanding adhesion at the interface [7] and cost effectiveness of the process [8]. Moreover, the polymeric support offers the advantage in weight, elasticity, fragility and flexibility [7].

Out of the varieties of polymeric materials available, polyimides are well known to show the most promising blend of the thermal and the mechanical properties [8]; consequently, they possess thermal stability, good filmforming ability, low dielectric constant [9], high chemical resistance, low coefficient of thermal expansion and high 
mechanical strength [10-13]. Polyimides are used as highperformance engineering plastics and are considered well applicable for high-performance material [14]. Due to these reasons polyimides are largely used as matrix for various purposes and the advantages of polyimide have been exploited as substrate to deposit transparent conducting oxide (TCO) film over it. ITO $\left(\operatorname{In}_{2} \mathrm{O}_{3}: \mathrm{Sn}\right)$ is one of the most intensively used TCO so far for excellent substrate adherence, high stability and chemical inertness [15]. Various physical and chemical methods based on different principles and processes are available for deposition of ITO thin films, i.e., sol-gel [16], spray pyrolysis [17-19], chemical vapor deposition [20] etc. Hence, it is worthy to mention here that an improved version of the pyrolysis technique is the socalled pyrosol or nebulized spray pyrolysis, which uses the transport by a carrier gas and the subsequent pyrolysis of a spray generated by an ultrasonic atomizer [21].

We have chosen this method of deposition due to its simplicity and considerably low cost for the fabrication of the conducting films. In several publications the ITO thin film deposited on glass and Si substrate are studied [15]; but the study of ITO deposition on PI substrate is not well reported especially in terms of chemical spray pyrolysis procedure.

In this study indium and tin chlorides were used as precursors for obtaining ITO films by a high temperature annealing. There are several factors responsible for the growth of ITO on a desired substrate like concentration of the salt solutions, spray volume per unit time, effect of solvents, nature of the particular substrate, etc. In the reported case, we have investigated only the effect of the substrate temperature on the growth of the ITO film keeping other factors constant. The film composition was investigated using powder X-ray diffraction (PXRD) and other electrical and optical properties of ITO films were compared according to substrate temperature. For better understanding the microstructure and surface morphology of these films, SEM, EDAX, and AFM analyses have also been performed.

\section{Methods}

Pyromellitic dianhydride (PMDA) $(97 \%)$ and 4,4'-oxydianiline (ODA) (97\%) were vacuum dried before use. N,Ndimethylacetamide (DMAc) (extra pure) was left over phosphorous pentoxide (97\%) and subsequently vacuum distilled freshly before use. Tin (IV) chloride pentahydrate (97\%) and Indium (III) chloride anhydrous (98\%) were used as received without any further purification. All the above reagents were purchased from Sigma Aldrich except DMAc which was procured from E. Merck, India. All other solvents used were of analytical reagent grade.

\section{Preparation of polyimide film substrate}

The polyimide synthesis was done adopting a well-known two step method as reported in the literature; the first step was that of synthesizing a viscous gel like precursor, i.e., polyamic acid (PAA) by taking the $1: 1$ ratio of the monomers [22] and carrying out a subsequent polycondensation reaction as shown in the Fig. 1. The second step involved the thermal cycloimidization of the PAA at $300{ }^{\circ} \mathrm{C}$. A three necked flask was flame dried and purged with dry nitrogen gas to eliminate any trace of moisture prior to the addition of the reagents to the flask. The PMDA-ODA polyamic acid was synthesized by slow addition of PMDA (10.90 g, $50 \mathrm{mmol})$ to ODA (10.12 g, $50 \mathrm{mmol})$ dissolved in dry DMAc $(95 \mathrm{ml})$. The reaction mixture was vigorously stirred with a mechanical stirrer till the complete addition of the dianhydride to the flask kept at ice bath under inert atmosphere. The clear viscous gel of polyamic acid so obtained was stirred for another $12 \mathrm{~h}$ to ensure the completion of the reaction. Then free standing films of PAA were casted on a clean grease free glass plate using a universal film applicator in a dust free chamber. The films so prepared were peeled off from the glass plate and cured up to $400{ }^{\circ} \mathrm{C}$ in a programmable oven at a heating rate of $2{ }^{\circ} \mathrm{C} / \mathrm{min}$ to get the required PI film (thickness: $80 \mu \mathrm{m}$ ) for further use as a substrate.

\section{ITO coating by spray pyrolysis}

ITO films were deposited by an advanced chemical spray pyrolysis technique using highly sophisticated and fully computerized Holmarc spray pyrolysis equipment Model No. HO-TH-04 [15, 23] from aqueous solutions of $\mathrm{SnCl}_{4} .5 \mathrm{H}_{2} \mathrm{O}$ and $\mathrm{InCl}_{3}(50 \% \mathrm{w} / \mathrm{w})$, using compressed air as carrier gas. Small pieces (dim: $2 \times 2 \mathrm{~cm}^{2}$ ) of ultrasonically cleaned polyimide films were used as a substrate on which ITO films were grown. The $80 \mu \mathrm{m}$ PI films were placed on a solid uniform thermally conducting surface to provide proper uniform heating. Total $20 \mathrm{ml}$ of the solution was sprayed at the rate of $1 \mathrm{ml} / \mathrm{min}$ in all the cases. A heater was used to provide deposition temperatures $\left(T_{\mathrm{dep}}\right)$ around 400,450 , and $500{ }^{\circ} \mathrm{C}$ to the PI films labeled as S1, S2, and S3, respectively. ITO film deposition was carried on heated substrates and annealing of samples was done above ITO crystallization temperature range $\left(T>200{ }^{\circ} \mathrm{C}\right)$. Heating was continued for $30 \mathrm{~min}$ at $T_{\text {dep }}$ to ensure complete pyrolysis of the precursor materials. A heavy duty fume scrubber was fitted with the spray pyrolysis equipment for the efficient removal of emitted corrosive gasses during the reaction. After pyrolysis, all the samples were heated in a programmable oven at a rate of $10{ }^{\circ} \mathrm{C} / \mathrm{min}$ up to $400{ }^{\circ} \mathrm{C}$, held for $30 \mathrm{~min}$ in air, cooled down to room temperature and then annealed at $500{ }^{\circ} \mathrm{C}$ for $1 \mathrm{~h}$. Thickness 
Fig. 1 Synthetic route for the preparation of PMDA-ODA polyimide deposition<smiles>Nc1ccc(Oc2ccc(N)cc2)cc1</smiles>

Pyromellitic dianhydride (PMDA) 4,4'-Oxydianiline (ODA)

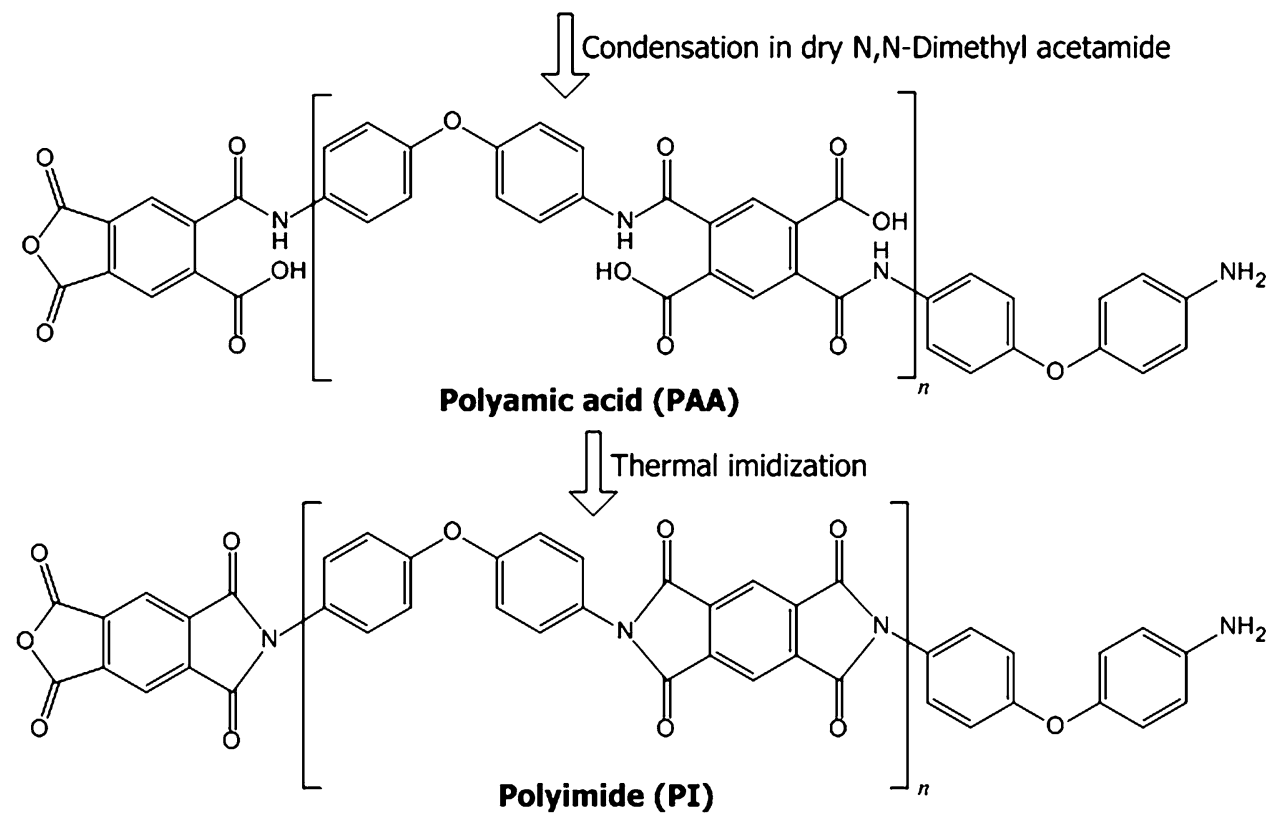

Polyimide (PI)

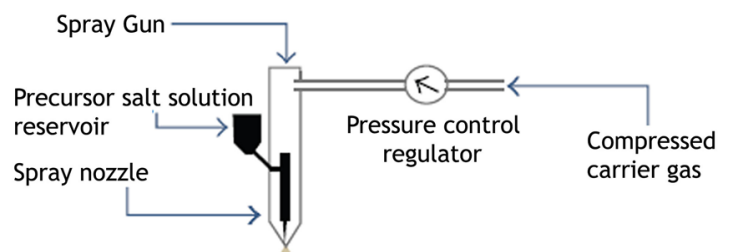

\section{Results and discussion}

Conducting metal oxide, ITO films were deposited by chemical spray pyrolysis on PMDA-ODA PI substrates at different temperatures to study the effect of substrate temperature on the physical, optical and electronic properties of the film. The coated films were characterized by UV-Vis spectroscopy, SEM, AFM, EDX, and PXRD. Overall thermal stability and the surface electrical properties were also evaluated.

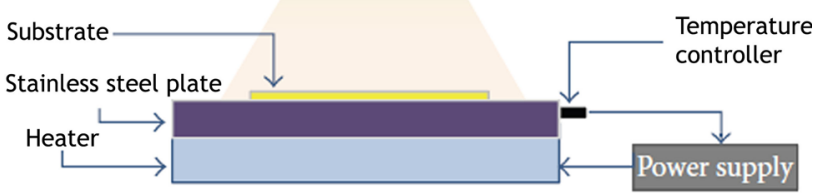

Fig. 2 Schematic diagram showing the outline of chemical spray pyrolysis procedure

Table 1 Various process parameters adopted for chemical spray pyrolysis

\begin{tabular}{lllllll}
\hline Sample & Solution used & Composition & $T_{\text {dep }}\left({ }^{\circ} \mathrm{C}\right)$ & Time $(\mathrm{min})$ & Flow rate $(\mathrm{ml} / \mathrm{min})$ & Annealing temp. $\left({ }^{\circ} \mathrm{C}\right)$ \\
\hline $\mathrm{S} 1$ & $\mathrm{SnCl}_{2} / \mathrm{InCl}_{3}$ (aq.) $20 \mathrm{ml}$ & $50 \% \mathrm{w} / \mathrm{w}$ & 400 & 45 & 1.0 & 500 \\
$\mathrm{~S} 2$ & $\mathrm{SnCl}_{2} / \mathrm{InCl}_{3}$ (aq.) $20 \mathrm{ml}$ & $50 \% \mathrm{w} / \mathrm{w}$ & 450 & 45 & 1.0 & 500 \\
$\mathrm{~S} 3$ & $\mathrm{SnCl}_{2} / \mathrm{InCl}_{3}$ (aq.) $20 \mathrm{ml}$ & $50 \% \mathrm{w} / \mathrm{w}$ & 500 & 45 & 1.0 & 500 \\
\hline
\end{tabular}




\section{UV-Vis spectroscopy}

Information regarding optical transmittance is important in evaluating the performance of conducting oxide films. Optical transmission spectra of the ITO-coated films were taken in unpolarized light at normal incidence in the wavelength range from 200 to $900 \mathrm{~nm}$, on a dual beam $\mathrm{UV}-\mathrm{Vis}$ spectrophotometer, taking the air as reference.

Figure 3 shows the $\%$ transmittance of the bare and the ITO-coated PI at different temperatures of deposition $\left(T_{\text {dep }}\right)$ 400,450 , and $500{ }^{\circ} \mathrm{C}$ plotted as S1, S2, and S3, respectively. Optical transmittance in the region 520-900 $\mathrm{nm}$ was found to be gradually improved with increasing substrate temperature, i.e., $9 \%$ for $400{ }^{\circ} \mathrm{C}(\mathrm{S} 1), 16 \%$ for $450{ }^{\circ} \mathrm{C}$ (S2) and $35 \%$ for $500{ }^{\circ} \mathrm{C}(\mathrm{S} 3)$, respectively, at $700 \mathrm{~nm}$. All the films showed $100 \%$ absorbance in the range of 200-520 $\mathrm{nm}$ and the UV absorption edges were located at approximately 600,550 and $527 \mathrm{~nm}$ for S1, S2 and S3, respectively. The improvement in optical transmittance can be attributed to the increase in structural homogeneity and crystallinity with higher substrate temperature [24]. Actually high temperature annealing leads to films with a steeper optical absorption curve and improvement in perfection and stoichiometry indicating a better crystallinity of the films and lower defect density near the band edge. A rougher surface constituted by grains with a higher average size was observed onto the polymer. Both the average roughness and the grain size were found to be lower at low substrate temperature. Such reduction in the grain size towards more amorphous state could be responsible for increased opaqueness, and consequently decreased transmittance for the ITO films prepared at the lower substrate temperature. However, to get more optical transmittance the polymeric substrate can be changed with some other

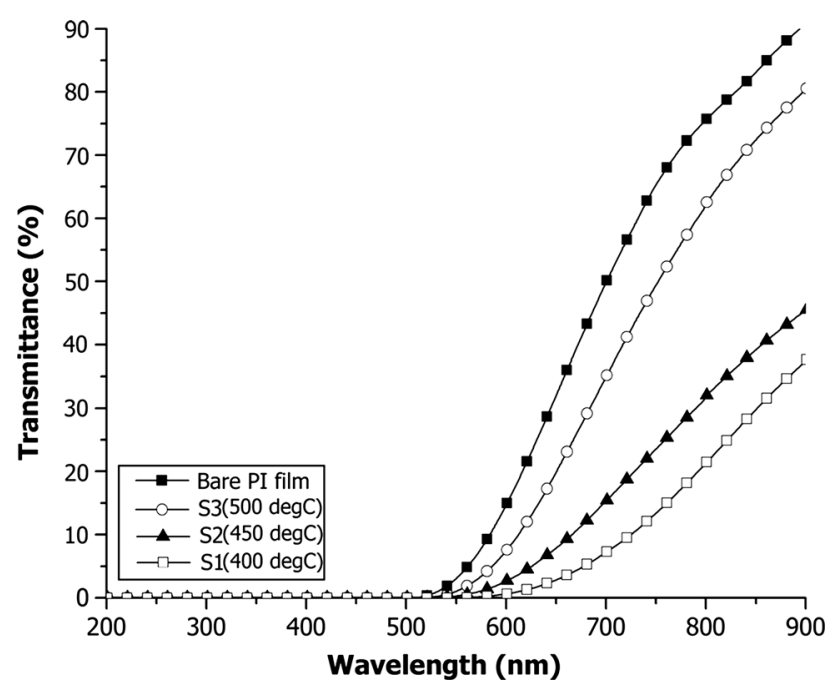

Fig. 3 Optical transmission spectra of bare PI and ITO coated varieties at different deposition temperatures more optically transparent one without compromising the mechanical properties. We are presently engaged in the $\mathrm{R} \& \mathrm{D}$ work to find appropriate polymeric substrates.

\section{ATR-FTIR spectroscopy}

Fourier transform infrared spectra were acquired to confirm complete thermal imidization of PAA films. The peak at $1637 \mathrm{~cm}^{-1}$ due to $v_{\text {str }}(-\mathrm{CONH})$ of PAA disappeared after imidization and some new peaks appeared in the polyimide which are as follows: (i) at $1782 \mathrm{~cm}^{-1}$ for $\mathrm{v}_{\text {asym }}(\mathrm{C}=\mathrm{O})$, (ii) a very sharp and strong band at $1719 \mathrm{~cm}^{-1}$ for $v_{\text {sym }}(C=O)$, overlapping with strong carboxylic acid band of $\mathrm{v}_{\mathrm{sym}}(\mathrm{C}=\mathrm{O})$ at $1690 \mathrm{~cm}^{-1}$ of PAA, (iii) peak at $3485 \mathrm{~cm}^{-1}$ due to the ( $\mathrm{C}=\mathrm{O}$ imide) overtone band [25], (iv) peaks at $1382 \mathrm{~cm}^{-1}$ and $3560 \mathrm{~cm}^{-1}$ due to $v_{\text {str }}(\mathrm{C}-\mathrm{N})$ [26] etc. A broad peak appeared around $3640 \mathrm{~cm}^{-1}$ may be attributed to the $v_{\text {str }}(\mathrm{O}-\mathrm{H})$ probably due to trapped moisture because polyimides have a tendency to absorb at least $2 \%$ water of its weight [27]. Appearance of a weak peak at $492 \mathrm{~cm}^{-1}$ was assigned to the vibrations of $\mathrm{In}-\mathrm{O}$ bonds and characteristic of cubic $\mathrm{In}_{2} \mathrm{O}_{3}$ phase [28].

\section{Compositional analysis by powder $\mathrm{X}$-ray diffraction}

$\mathrm{X}$-ray diffraction is a powerful tool to monitor a process as it can easily distinguish between various newly formed phases compared to that of the starting materials. Comparative Powder X-ray diffractogram (Fig. 4) of the ITOcoated flexible polyimide films at different substrate temperatures $\left(400,450\right.$, and $\left.500{ }^{\circ} \mathrm{C}\right)$ was compared in the $2 \theta$ range of $10^{\circ}-90^{\circ}$ to determine the chemical composition of the deposited film along with an estimation of the mean crystallite size.

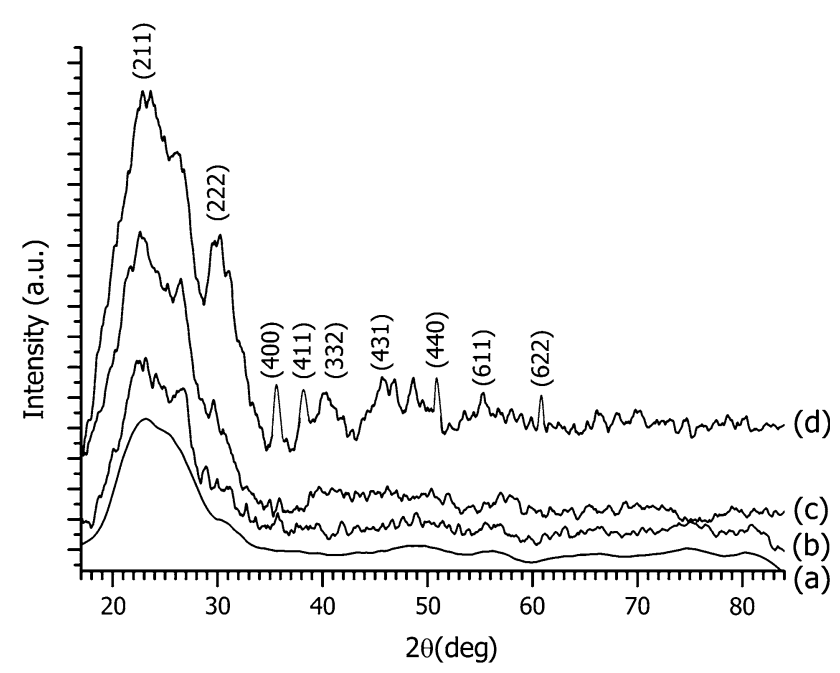

Fig. 4 XRD patterns of the ITO coated PI substrates: (a) bare PI, (b) at deposition temperature $400{ }^{\circ} \mathrm{C},(\mathbf{c})$ at deposition temperature $450{ }^{\circ} \mathrm{C}$, (d) at deposition temperature $500{ }^{\circ} \mathrm{C}$ 
The PXRD patterns of the ITO-coated samples show a well defined (222) peak and to evidence other peaks, the pattern in the region $30^{\circ}-60^{\circ}$ was registered with a higher sensitivity. The films show the maximum intensity peak corresponding to the (222) orientation around $30.581^{\circ}$ which is reported as favored direction of the grain growth observed for polycrystalline ITO films with higher oxygen content [29]. All other peaks observed were (211), (400), (411), (332), (431), (440), (611), and (622) appearing at $21.501^{\circ}, 35.467^{\circ}, 37.690^{\circ}, 41.846^{\circ}, 45.690^{\circ}, 51.064^{\circ}$, $55.990^{\circ}$, and $61.680^{\circ}$, respectively. The pattern is indicative of only crystalline ITO with body centered cubic bixbyite structure (JCPDS card no. 06-0416 [30]). A broad hump centered at $2 \theta$ range lower than $30^{\circ}$, indicates a short range molecular order and relatively low crystalline nature of the aromatic polyimides. The uneven baseline in all these cases may be attributed to the presence of a large amount of amorphous polymer component in background and the pattern with diffused peak structure which is typical of nanocrystalline materials [31]. The comparison shows that the peaks are suppressed for the films deposited at lower temperature where an improvement of crystallinity and grain size was observed with increasing substrate temperature. The pattern corresponding to the characteristic peaks of stoichiometric $\operatorname{In}_{2} \mathrm{O}_{3}$, implied substitutional replacement of indium by tin in the lattice. No phases corresponding to tin oxide or other tin compounds were detected. Indium oxide $\left(\mathrm{In}_{2} \mathrm{O}_{3}\right.$, so-called bixbyite) is a cubic system with the space group, $T_{\mathrm{h}}^{7} \mathrm{Ia} 3$ and lattice parameter, $a=10.117 \AA$ at $25{ }^{\circ} \mathrm{C}[24,40]$. According to the JCPDS card, the interplanar spacing is $d_{0}(222)=2.921(2) \AA$, and the diffraction intensities ratio $\mathrm{I}(222) / \mathrm{I}(400)=3.33$ which are in good agreement with our data $\left[d_{0}(222)=2.970(2) \AA\right.$ and $\left.\mathrm{I}(222) / \mathrm{I}(400)=3.49\right]$. The grain size of the polycrystalline ITO films was calculated using the Scherrer's formula (assuming the spherical grain shape):

$D=\frac{K \times \lambda}{\beta(2 \theta)^{c} \times \cos \theta}$

where $D$ is the diameter of the grains in $\mathrm{nm}, \lambda$ is the wavelength of the X-ray in nm, $\beta$ is the full width at half maximum (FWHM) in radian, $\theta$ is the Bragg's diffraction angle in degree, and $K=0.94$. The mean crystallite grain size estimated using the above equation was found to be 20.7, 45.2, and $80.6 \mathrm{~nm}$ for S1, S2, and S3, respectively.

\section{Surface morphology analysis by scanning electron microscopy and EDAX}

Scanning electron microscopy (SEM) (Fig. 5) was used to examine the surface morphology of the ITO films deposited on the flexible PI substrates. In all the cases a web like morphology was observed. Better and more compact deposition of ITO films was observed at higher substrate temperature, though the material distribution was predominantly inhomogeneous.

EDAX area and spot analyses of the ITO films were done (Fig. 6) and it showed the presence of $\mathrm{Sn}$ and In nuclei homogeneously distributed all over the PI substrate. At $\%$ ratio of $\mathrm{Sn}$ :In was found to be $\sim 1.12$ in all the cases. Indium tin oxide is essentially formed by substitutional doping of $\mathrm{In}_{2} \mathrm{O}_{3}$ with $\mathrm{Sn}$ replacing the $\mathrm{In}(\mathrm{III})$ atoms from the cubic bixbyite structure of indium oxide [32]. However, in ITO both substitutional tin and oxygen vacancies contribute to the conductivity [33, 34]. A representative quantitative elemental analysis of the films is as follows: Sn/L: In/L: O/K: $\mathrm{C} / \mathrm{K}=04.54:$ 04.16: 37.85: 53.46 in atomic wt $\%$. Excess at wt $\%$ of carbon and oxygen probably come from the underneath polymeric substrate.

\section{Surface topography analysis by atomic force microscopy}

The $5 \times 5 \mu^{2}$ atomic force microscopy (AFM) images support the influence of substrate temperature on the surface topography of the ITO thin films deposited on PI substrate as well as morphology of the grains (Fig. 7). AFM data in the form of average surface roughness values found from these images are represented in Table 2. A rougher surface constituted by grains with a higher average grain size was observed with increasing substrate temperature. The grains possess different irregular shapes, sizes and separations. Another notable feature was the evolution of the interface width as a function of deposition temperature, where valleys, mountains, and island clusters become larger as the temperature increases. The increment in the grain size may be responsible for decreased optical scattering [35], and consequently increased transmittance that is detected in the reported case for the ITO films prepared at the higher substrate temperature.

A few important parameters were extracted from the AFM measurements and obtained for the mapping areas of the $5 \times 5 \mu \mathrm{m}^{2}$ as follows: (i) the root-mean-square (RMS) roughness $\left(R_{q}\right)$, which gives the root-mean-square average of height deviations taken from the mean data plane within a given area; (ii) the mean roughness $\left(R_{a}\right)$, which represents the arithmetic average of the absolute values of the surface height deviations measured from the mean plane and (iii) the average differences of heights $\left(h_{\text {avg }}\right)$.

The ITO film roughness, characterized by the above set of parameters increases (all parameters exhibit the similar trend) at higher deposition temperatures (Table 2). The observed trend mentioned above may be explained by spray pyrolysis film growth. The vapor phase growth mechanisms in this method (droplet evaporation; gas phase 

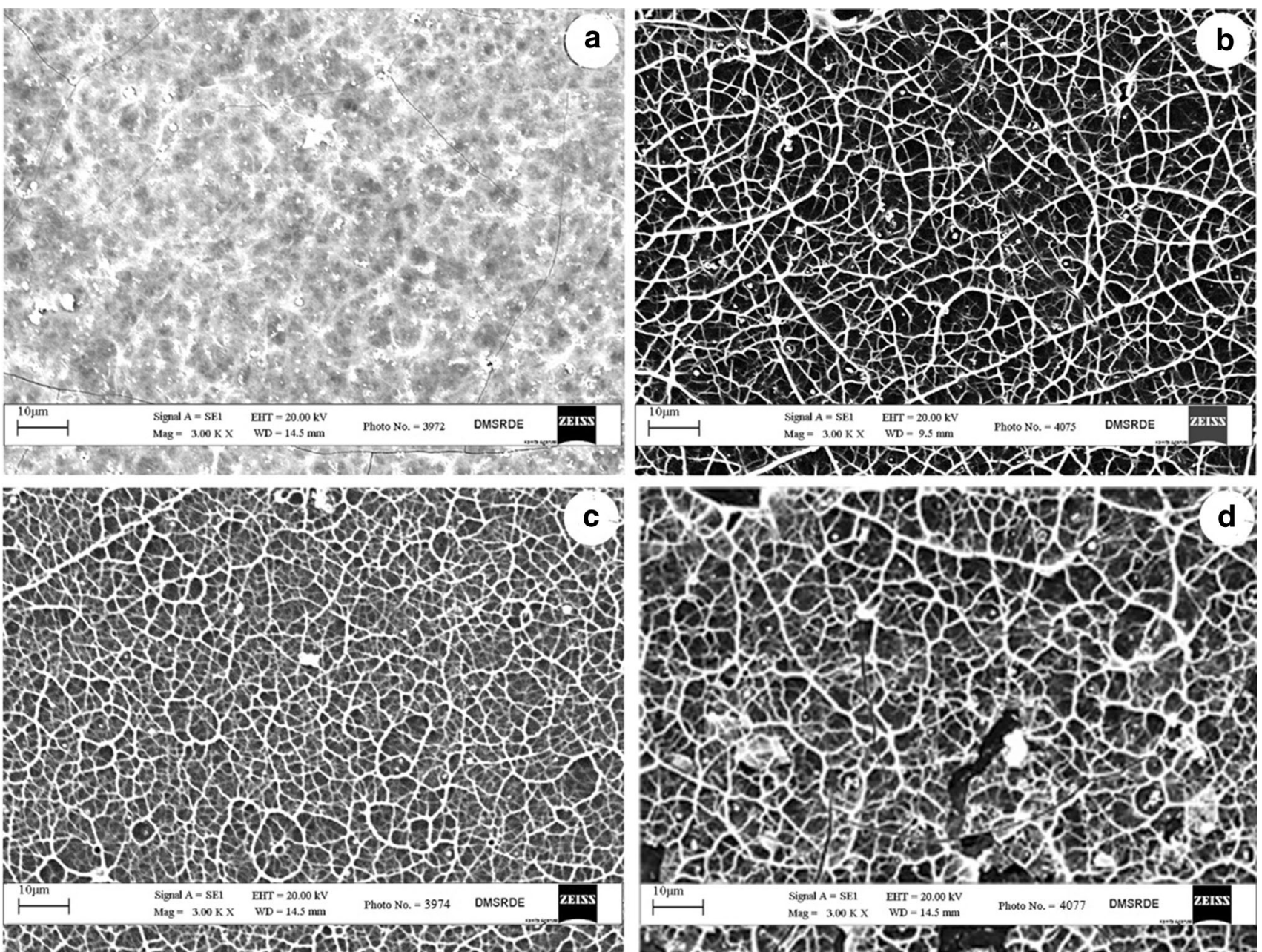

Fig. 5 SEM images of the ITO coated PI substrates: a at deposition temperature $400{ }^{\circ} \mathrm{C}$, b at deposition temperature $450{ }^{\circ} \mathrm{C}$, $\mathbf{c}$ at deposition temperature $500{ }^{\circ} \mathrm{C}, \mathbf{d}$ surface view of sample S3 after peel off test
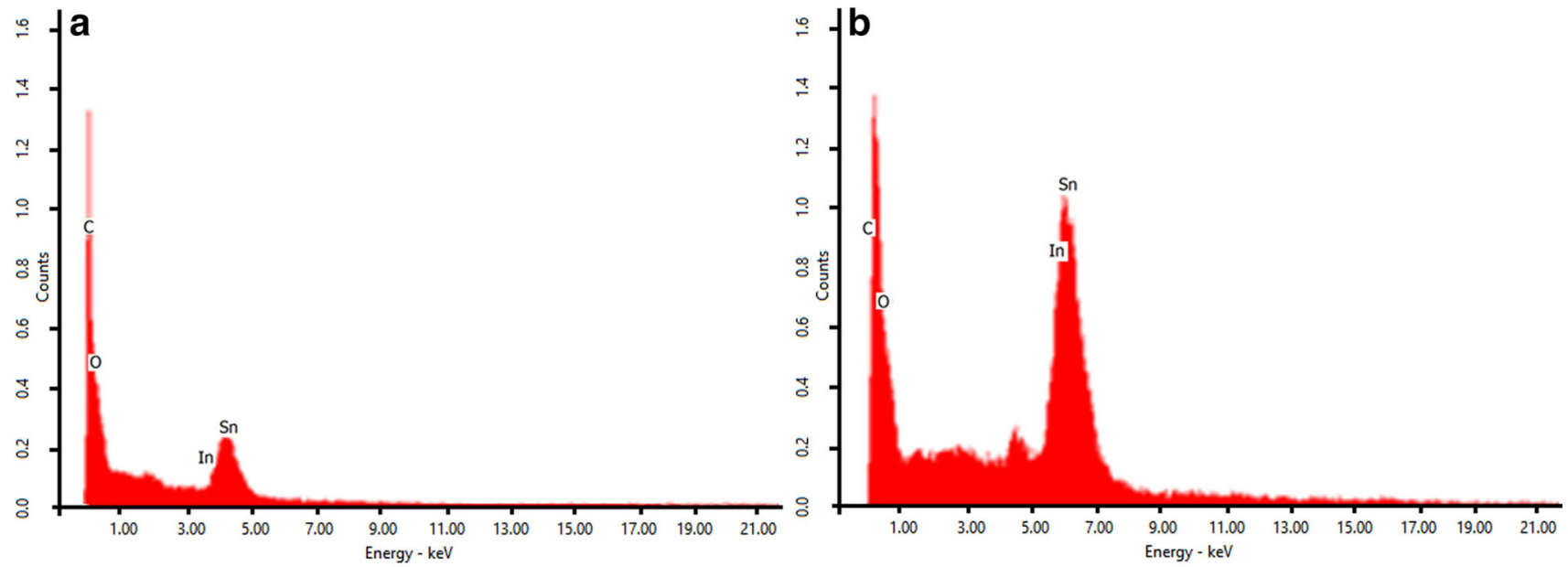

Fig. 6 EDAX patterns (area analysis) of the ITO coated PI substrates: a at deposition temperature $400{ }^{\circ} \mathrm{C}$, $\mathbf{b}$ at deposition temperature $500{ }^{\circ} \mathrm{C}$ 

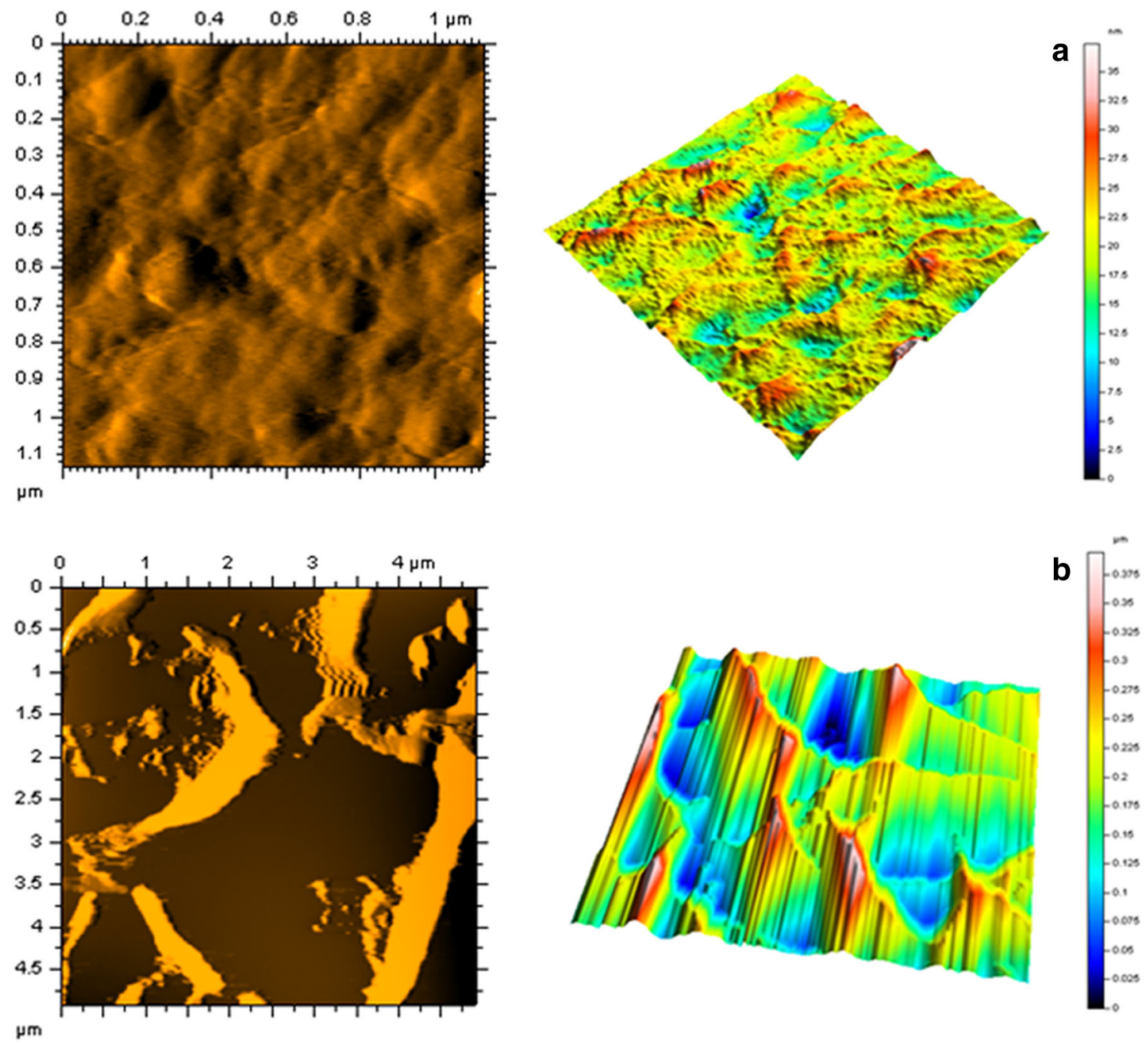

Fig. 7 3D-AFM images of the ITO coated PI substrates: a at deposition temperature $400{ }^{\circ} \mathrm{C}, \mathbf{b}$ at deposition temperature $500{ }^{\circ} \mathrm{C}$

Table 2 AFM data for ITO films deposited on PI substrates at different deposition temperatures

\begin{tabular}{lllll}
\hline Topography & $T_{\text {dep }}\left({ }^{\circ} \mathrm{C}\right)$ & $R_{q}(\mathrm{~nm})$ & $R_{a}(\mathrm{~nm})$ & $h_{\text {avg }}(\mathrm{nm})$ \\
\hline Indium tin oxide film on PI substrate & 400 & 1.7865 & 1.5279 & 3.5201 \\
& 450 & 1.9223 & 1.6606 & 3.6463 \\
& 500 & 2.4249 & 2.1362 & 4.3202 \\
\hline
\end{tabular}

\section{Thermogravimetric analyses}

Thermogravimetric analyses (TGA) were performed at a heating rate of $10^{\circ} \mathrm{C} / \mathrm{min}$ in air. TGA curves for bare PI and its ITO deposited varieties at different substrate temperatures are shown in Fig. 8 and the related data have been presented in the Table 3 .

All the samples experienced a two step mass loss under programmable heating, i.e., Moisture de-trapping: an initial loss (approx. $1.7 \%$ ) of mass due to trapped moisture between 60 and $175^{\circ} \mathrm{C}$; Carbonization: A major steep mass loss (approx. 35\%) which commences around heating at higher annealing temperature. 


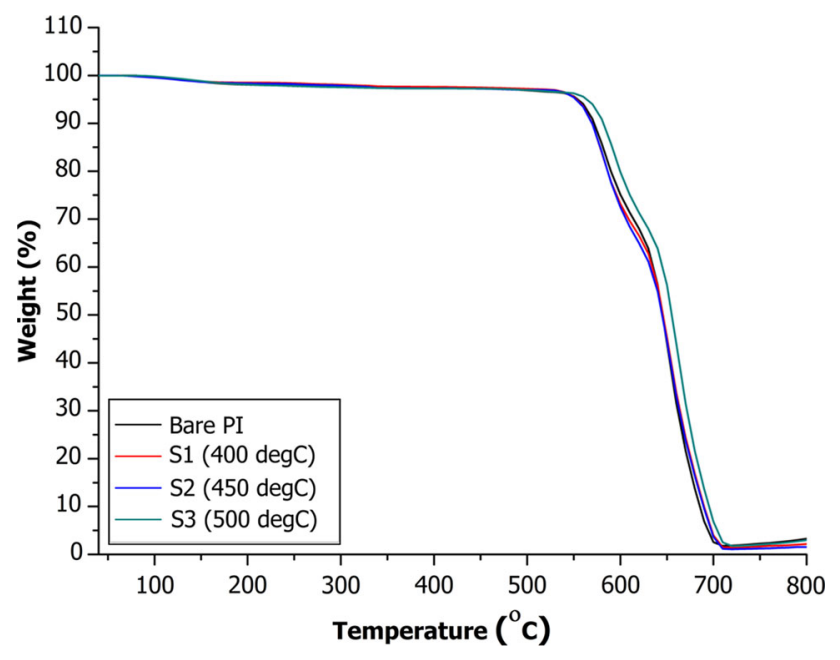

Fig. 8 TG curves of the bare PI and ITO coated PI substrates at deposition temperatures at 400,450 and $500{ }^{\circ} \mathrm{C}$

$543{ }^{\circ} \mathrm{C}$ and completes at $714{ }^{\circ} \mathrm{C}$, with the maximum decomposition rate $\left(T_{\max }\right)$ around $600{ }^{\circ} \mathrm{C}$. The polymer decomposition temperature (PDT, which denotes the temperature at $10 \%$ mass loss) was observed at around $570{ }^{\circ} \mathrm{C}$ and only a mere difference of $5{ }^{\circ} \mathrm{C}$ was found between the bare PI and its ITO deposited varieties. The data in Table 3 suggests that the incorporation of ITO layers on the surfaces of PI film does not diminish the bulk polymer structure significantly compared with the original PI, thus keeping the overall thermal stability uninterrupted in all the cases. The ITO-coated flexible PI films retain the essential properties of the pristine PI, which would probably attribute to the intact inner bulk of the PI matrix [31].

\section{Electrical properties}

Surface electrical resistivity of the ITO films annealed at different temperatures was measured using four-point probe technique. It is shown that the resistivity reveals strong dependence on the substrate temperature. The ITO films reported herein exhibit resistivity value of $10.540 \times 10^{-3}$, $8.323 \times 10^{-3}$ and $7.957 \times 10^{-3} \Omega \mathrm{cm}$ at the deposition temperature of 400,450 , and $500{ }^{\circ} \mathrm{C}$, respectively, compared to highly resistive bare PI substrate. Higher deposition temperature influences the film micro-structure and surface roughness as also revealed through AFM, leading to the decrease in surface resistivity $[37,38]$. The obtained resistivity values of the ITO films are found to be slightly higher than the values obtained by Hao et al. [39] for ITO/PET system. This may be ascribed to the relatively less crystalline structure of the obtained films. In amorphous grain morphology, some electrons are bound in short range by the net non-uniform structure. As the structure of the films becomes more and more crystalline, these electrons are released from the bound. Other factor which can account for the higher resistivity is the possibility of microscopic cracks formation in the ITO layer during spray pyrolysis [22]. Therefore, to get ITO films of low resistivity, one needs to enhance the crystallinity of the deposited films from the initial stage of deposition on the polymer substrate as it is envisaged from the upward trend of surface electrical conductivity with higher substrate temperature and thereby higher crystallinity in the reported case.

The lower resistivity therefore higher conductivity shown by ITO deposited on polymer substrate at higher temperature could be related to the higher ITO average grain size, thus increasing mobility by decreasing the grain boundaries that can act as carrier scattering centers [9]. Therefore, increasing substrate temperature increases the dense and compactness of the ITO films and thereby less defects and higher conductivity obtained [40].

\section{Adhesion properties}

Adhesion test was performed on the films as per ASTMB905 standard after bending. The scotch tape peel off test was conducted on the deposited thin film on the PI substrate via spray pyrolysis, using transparent adhesive tape. The tape was adhered to the ITO deposited PI film and was peeled off from it. The SEM micrographs of the samples were collected before and after the peel off test. No significant change in the surface morphology of the deposited film was observed after the peel off test which suggests that the bonding was fairly strong. These results can be explained on the basis of the van der Waal's interaction between the metal oxide film and the PI substrate [41].

Table 3 Comparison of TGA data of bare PI and its ITO-coated varieties at different deposition temperatures

\begin{tabular}{llllll}
\hline Sample & $T_{\text {dep }}\left({ }^{\circ} \mathrm{C}\right)$ & $\begin{array}{l}5 \mathrm{wt} \% \text { loss } \\
\text { temp. }\left({ }^{\circ} \mathrm{C}\right)\end{array}$ & $\begin{array}{l}10 \mathrm{wt} \% \text { loss } \\
\text { temp. PDT }\left({ }^{\circ} \mathrm{C}\right)\end{array}$ & $\begin{array}{l}T_{\max } \\
\text { Char yield at } \\
800{ }^{\circ} \mathrm{C}(\%)\end{array}$ \\
\hline Bare PI & Not applicable & 550 & 570 & 600 & 60 \\
S1 & 400 & 554 & 572 & 600 & 62 \\
S2 & 450 & 558 & 580 & 599 & 63 \\
S3 & 500 & 560 & 583 & 600 \\
\hline
\end{tabular}




\section{Characterization}

The optical characteristics of the films were determined by a Varian Cary 5000 UV-Vis double beam spectrophotometer in the wavelength range of $200-900 \mathrm{~nm}$. Attenuated total reflection Fourier transform infrared (ATR-FTIR) spectra were recorded in the range of $4000-400 \mathrm{~cm}^{-1}$ on a PerkinElmer Spectrum TWO ATR-FTIR spectrometer. The thermogravimetric analyses were performed using a TA instrument, USA (TGA-2950) TG-analyser under an air atmosphere, with a heating rate of $10^{\circ} \mathrm{C} / \mathrm{min}$ from 30 to $800{ }^{\circ} \mathrm{C}$. Scanning electron microscopy (SEM) images of the samples were acquired on a Carl Zeiss EVO-50 Low Vacuum SEM. Energy dispersive X-ray (EDX) analysis was done on the EDAX system (Zeiss X-flash detector analyzer, associated with SEM equipment) using incident electron beam energies of $20 \mathrm{kV}$, operating at WD $9.0 \mathrm{~mm}$ for the determination of the chemical composition of the deposited ITO films. PXRD measurements were performed with a PXRD Miniflex Model, Rigaku, Japan) with monochromatic $\mathrm{Cu}-\mathrm{K} \alpha$ radiation $(\lambda=1.54056 \AA, 40 \mathrm{kV}$ at $40 \mathrm{~mA})$ in the $2 \theta$ range of $10^{\circ}-90^{\circ}$ with step size of $0.2^{\circ}$. Atomic force microscopy (AFM) was carried out using an Agilent Technologies AFM (Model 5500) in non-contact mode. The samples were mounted on the XY stage of the AFM. Micro fabricated silicon nitride cantilevers with the resonant frequency of $80 \mathrm{kHz}$ were used. The values of surface electrical resistance of the films were recorded by a Keithley four probe Electrometer with a four-point probe head at room temperature.

\section{Conclusions}

ITO films were deposited on flexible polyimide substrate by chemical spray pyrolysis. The substrate temperatures play an important role in controlling the physical, morphological, optical and electrical characteristics of the films. ITO films, thus deposited on polyimide substrate at higher deposition temperature, have larger grain sizes, a high surface roughness and a low surface resistivity. Films are polycrystalline indium oxide with a cubic bixbyite structure. There was no evidence of tin compounds like $\mathrm{SnO}, \mathrm{SnO}_{2}$, etc., in the X-ray diffractogram. ITO films prepared by chemical spray pyrolysis process reported herein exhibit properties of both good optical transparency and low electrical resistivity which are comparable to those prepared by other methods.

Acknowledgments We would like to thank the support from the Director, DMSRDE, Kanpur for providing the required resources and giving R. Rana an opportunity to carry out her project work as a partial fulfillment of B. Tech. degree. Thanks are also due to Dr. R. S. Anand, Indian Institute of Technology, Kanpur for his kind cooperation regarding characterization facilities. Above R \& D work has been carried out with full financial assistance from the Defence Research and Development Organization (DRDO), Government of India, Ministry of Defence, New Delhi.

Authors' contributions RR carried the studies under the supervision of SKT and MN. JC has analysed and interpreted the experimental data, written and revised the manuscript critically for important intellectual content. All authors read and approved the final manuscript uploaded for communication.

\section{Compliance with ethical standards}

Conflict of interest All authors declare that they have no competing interests.

Open Access This article is distributed under the terms of the Creative Commons Attribution 4.0 International License (http://creative commons.org/licenses/by/4.0/), which permits unrestricted use, distribution, and reproduction in any medium, provided you give appropriate credit to the original author(s) and the source, provide a link to the Creative Commons license, and indicate if changes were made.

\section{References}

1. Cui, G., Wu, D., Qi, S., Jin, S., Wu, Z., Jin, R.: Preparation of $\mathrm{SnO}_{2}$ nanolayer on flexible polyimide substrates via direct ion exchange and in situ oxidation process. Appl. Mater. Interfaces 3, 789-794 (2011)

2. Guillén, C., Herrero, J.: Transparent electrodes based on metal and metal oxide stacked layers grown at room temperature on polymer substrate. Phys. Status Solidi A 207, 1563-1567 (2010)

3. Shirahata, N., Hozumi, A.: Etchingless micro fabrication of a thick metal oxide film on a flexible polymer substrate. Chem. Mater. 17, 20-27 (2005)

4. Yang, S., Wu, D., Qi, S., Cui, G., Jin, R., Wu, Z.: Fabrication of highly reflective and conductive double-surface-silvered layers embedded on polymeric films through all-wet process at room temperature. J. Phys. Chem. B 113, 9694-9701 (2009)

5. Ektessab, A.M., Hakamata, S.: XPS study of ion beam modified polyimide films. Thin Solid Films 377-378, 621-625 (2000)

6. Matienzo, L.J., Unertl, W.N.: Adhesion of Metal Films to Polyimides, p. p3523. Marcel Dekker, New York (1996)

7. Southward, R.E., Thompson, D.W.: Reflective and conductive silvered polyimide films for space applications prepared via a novel single-stage self-metallization technique. Mater. Des. 22, 565-576 (2001)

8. Lozano, A.E., de Abajo, J., de la Campa, J.G., Guillén, C., Herrero, J., Gutiérrez, M.T.: Thin film polyimide/indium tin oxide composites for photovoltaic applications. J. Appl. Polym. Sci. 103, 3491-3497 (2007)

9. Mu, S., Wu, D., Wang, Y., Wu, Z., Yang, X., Yang, W.: Fabrication of nickel oxide nanocomposite layer on a flexible polyimide substrate via ion exchange technique. Appl. Mater. Interfaces 2, 111-118 (2010)

10. Ghosh, K.L., Mittal, K.L.: Polyimides: Fundamentals and Applications, p. p4326. Marcel Dekker, New York (1996)

11. Philipp, G., Schmidt, H.: The reactivity of $\mathrm{TiO}_{2}$ and $\mathrm{ZrO}_{2}$ in organically modified silicates. J. Non Cryst. Solids 82, 31-36 (1986)

12. Kreuz, J.A., Edman, J.R.: Polyimide films. Adv. Mater. 10, 1229-1232 (1998)

13. Hasegawa, M., Horie, K.: Photophysics, photochemistry, and optical properties of Polyimides. Prog. Polym. Sci. 26, 259-335 (2001) 
14. Chen, D., Wang, R., Tjiu, W.W., Lui, T.: High performance polyimide composite films prepared by homogeneity reinforcement of electrospun nanofibers. Compos. Sci. Technol. 71, 1556-1561 (2011)

15. Chebotareva, A.B., Untila, G.G., Kost, T.N., Jorgensen, S., Ulyashin, A.G.: ITO deposited by pyrosol for photovoltaic applications. Thin Solid Films 515, 8505-8510 (2007)

16. Gurlo, A., Ivanovskaya, M., Pfau, A., Weimar, U., Göpel, W.: Sol-gel prepared $\mathrm{In}_{2} \mathrm{O}_{3}$ thin films. Thin Solid Films 307, 288-293 (1997)

17. Blandenet, G., Court, M., Lagarde, Y.: Thin layers deposited by the pyrosol process. Thin Solid Films 77, 81-90 (1981)

18. Manifacier, J.C., Fillard, J.P., Bind, J.M.: Deposition of $\operatorname{In}_{2} \mathrm{O}_{3}-$ $\mathrm{SnO}_{2}$ layers on glass substrates using a spraying method. Thin Solid Films 77, 67-80 (1981)

19. Zhou, Z.B., Cui, R.Q., Pang, Q.J., Wang, Y.D., Meng, F.Y., Sun, T.T., Ding, Z.M., Yu, X.B.: Preparation of indium tin oxide films and doped tin oxide films by an ultrasonic spray CVD process. Appl. Surf. Sci. 172(3-4), 245-252 (2001)

20. Maruyama, T., Tabata, K.: Indium tin oxide thin films prepared by chemical vapor deposition from metal acetates. Jpn. J. Appl. Phys. 29, L355-L357 (1990)

21. Rao, C.N.R.: Chemical approaches to the design of oxide materials. Pure Appl. Chem. 66, 1765-1772 (1994)

22. Jain, N., Chakraborty, J., Tripathi, S.K., Nasim, M.: Fabrication and characterization of in situ synthesized iron oxide-modified polyimide nanoweb by needleless electrospinning. J. Appl. Polym. Sci. 131, 40432-40441 (2014)

23. Isac, L., Duta, A., Kriza, A.: Copper sulfides obtained by spray pyrolysis-possible absorbers in solid-state solar cells. Thin Solid Films 15, 5755-5758 (2007)

24. Hamberg, I., Granqvist, C.G.: Evaporated Sn-doped $\mathrm{In}_{2} \mathrm{O}_{3}$ films: basic optical properties and applications to energy-efficient windows. J. Appl. Phys. 60, R123-R160 (1986)

25. Jamal, K., Ashwani, K.: Synthesis and characterization of modified bismaleimide/polysulfone semi-interpenetrating polymer networks. J. Polym. Sci. 102, 369-379 (2006)

26. Singh, B.P., Singh, D., Mathur, R.B., Dhami, T.L.: Influence of surface modified MWCNTs on the mechanical, electrical and thermal properties of polyimide nanocomposites. Nanoscale Res. Lett. 3, 444-453 (2008)

27. Musto, P., Mascia, L., Mensitieri, G., Ragosta, G.: Diffusion of water and ammonia through polyimide-silica bicontinuous nanocomposites: interactions and reactions. Polymer 46, 4492-4503 (2005)
28. Zhi-hua, L., Yu-Peng, K., Dong-Yan, R.: Effects of heat treatment on morphological, optical and electrical properties of ITO films by sol-gel technique. Trans. Nonferrous Met. Soc. China 18, 366-371 (2008)

29. Hoshi, Y., Kato, H., Funatsu, K.: Structure and electrical properties of ITO thin films deposited at high rate by facing target sputtering. Thin Solid Films 445, 245-251 (2003)

30. International Centre for Diffraction Data (ICDD). PDF-2 Release. 2008

31. Mu, S., Wu, Z., Wang, Y., Qi, S., Yang, X., Wu, D.: Formation and characterization of cobalt oxide layers on polyimide films via surface modification and ion exchange technique. Thin Solid Films 518, 4175-4182 (2010)

32. Mohamed, S.H., El-Hossary, F.M., Gamal, G.A., Kahlid, M.M.: Properties of Indium Tin Oxide thin films deposited on polymer substrates. Acta Phys. Pol. A 115(3), 704-708 (2009)

33. Kim, D., Han, Y., Cho, J.S., Koh, S.K.: Low temperature deposition of ITO thin films by ion beam sputtering. Thin Solid Films 377-378, 81-86 (2000)

34. Ali, M.K.M., Ibrahim, K., Hamad, O.S., Eisa, M.H., Faraj, M.G., Azhari, F.: Deposited indium tin oxide (ITO) thin films by dcmagnetron sputtering on polyethylene terephthalate substrate (PET). Rom. J. Phys. 56, 730-741 (2011)

35. Purica, M., Iacomi, F., Baban, C., Prepelita, P., Apetroaei, N., Mardare, D., Luca, D.: Investigation of structural properties of ITO thin films deposited on different substrates. Thin Solid Films 515, 8674-8678 (2007)

36. Langlet, M.: Optically active coatings deposited from an ultrasonically generated aerosol. Thin Solid Films 71, 398-399 (2001)

37. Salehi, A.: The effects of deposition rate and substrate temperature of ITO thin films on electrical and optical properties. Thin Solid Films 324, 214-218 (1998)

38. Alam, M.J., Cameron, D.C.: Optical and electrical properties of transparent conductive ITO thin films deposited by sol-gel process. Thin Solid Films 377, 455-459 (2000)

39. Hao, L., Diao, X., Xu, H., Gu, B., Wang, T.: Appl. Surf. Sci. 254, 3504-3508 (2008)

40. Sato, Y., Taketomo, M., Ito, N., Miyamura, A., Shigesato, Y.: Comparative study on early stages of film growth for transparent conductive oxide films deposited by dc magnetron sputtering. Thin Solid Films 516, 4598-4602 (2008)

41. Zeng H.: Adhesion and Friction Mechanisms of Polymer Surfaces and Thin Films. Chapter 10, p 127: DOI:10.1002/ 9781118505175.ch10 